\title{
The effect of activin A on signal transduction pathways in PC12 cells subjected to oxygen and glucose deprivation
}

\author{
HONGLIANG GUO ${ }^{*}$, XIAORAN SHEN ${ }^{2 *}, \mathrm{YE} \mathrm{XU}^{3}$, YOUDI HE$^{1}$ and WENLI HU ${ }^{1}$ \\ ${ }^{1}$ Department of Neurology, Beijing Chaoyang Hospital Affiliated to Capital Medical University, Beijing 100020; \\ ${ }^{2}$ Jilin Municipal Central Hospital, Jilin 132001; ${ }^{3}$ Medical Research Laboratory, Jilin Medical College, Jilin 132013, P.R. China
}

Received July 15, 2013; Accepted October 2, 2013

DOI: $10.3892 /$ ijmm.2013.1539

\begin{abstract}
The processes and mechanisms underlying brain injuries due to ischemia and anoxia have yet to be determined. Additionally, few clinical treatements are currently available. Activins have a protective role in the restoration, differentiation, and survival of injured cells, including Activin A (ActA), which acts as a neuroprotectant. However, its exact mechanism of action remains to be determined. ActA has been shown to protect neurons following ischemic brain injury. In this study, PC12 cells were differentiated into neuron-like cells after stimulation with nerve growth factor to prepare an oxygen/glucose deprivation (OGD) model in neurons. The differentiated PC12 cells, subjected to the OGD model, were exposed to ActA. Results showed that the PC12 survival rate decreased after OGD, leading to an increase in caspase-3 expression in these cells. Pretreatment with ActA was able to partially prevent OGD-induced apoptosis, likely through the downregulation of caspase-3. Futhermore, ActA pretreatment increased the expression of key proteins in the ActA/Smads signal transduction pathway, which may promote neuroprotection after OGD. Therefore, exogenous ActA may function as a neuroprotectant and provide a novel therapeutic treatment for ischemic brain injury.
\end{abstract}

\section{Introduction}

The processes and mechanisms underlying brain injuries due to ischemia and anoxia remain to be elucidated. Additionally, few clinical treatments are currently available for these types of injury. Activins, which are widely distributed in the body, possess biological activity and are capable of regulating the

Correspondence to: Professor Wenli Hu, Department of Neurology, Beijing Chaoyang Hospital Affiliated to Capital Medical University, No. 8 Gongtinan Road, Chaoyan District, Beijing 100020, P.R. China E-mail: zz9722@sina.com

*Conributed equally

Key words: activin A, oxygen/glucose deprivation, $\mathrm{PC} 12$ restoration, differentiation and survival of injured cells. These molecules also promote tissue regeneration, participate in the processes of various diseases and exhibit marked tissue and organ specificity (1). Investigations into neuronal disorders have led to an increased interest in activin A (ActA), which acts as a recognized strong protectin in the nervous system (2). ActA is a member of the transforming growth factor (TGF) $\beta 1$ super-family (4-6), and transmits signals by binding to serine-threonine receptors on cell membranes (7). The activation of different ligands of ActA receptors may lead to different physiological and pathological effects in vivo. ActA has been shown to exert its effects through stimulation of the Smad signal transduction pathway (3), including Smad2 and Smad3. Receptor-regulated Smad proteins then form a multimer with Smad4, which translocates into the nucleus and co-regulates target gene transcription and other biological functions with intranuclear cofactors (8-10).

It is clear that exogenous activin plays a protective role in the nervous system. However, few studies have focused on the protective effect of ActA on neurons. Therefore, the aim of the present study was to elucidate the protective mechanism of action of Act $\mathrm{A}$ in an in vitro oxygen/glucose deprivation (OGD) model system. To this end, PC12 cells were differentiated into neuron-like cells and were then exposed to different concentrations of exogenous ActA. The effect of this treatment was assessed under anoxic and ischemic conditions on PC12 survival and caspase-3 expression, a key apoptotic regulatory protein.

\section{Materials and methods}

PC12 cell culture. PC12 cells (Beijing Chinese Redbud Biological Co. Ltd., Beijing, China) were plated into polylysine-coated flasks containing Dulbecco's modified Eagle's medium (DMEM; Gibco, Carlsbad, CA, USA). The cells were then incubated in a $5 \% \mathrm{CO}_{2}$ incubator at $37^{\circ} \mathrm{C}$, and their media were changed after two days. When the cells reached $85 \%$ confluence, they were used for the experiments.

PC12 cell differentiation. Glass coverslips were scratched and placed into 24-well plates. PC12 cells were inoculated into these wells at a concentration of $5 \times 10^{4}$ cells $/ \mathrm{ml}$ and cultivated for $24 \mathrm{~h}$. Nerve growth factor (NGF) diluted in DMEM $(0.05 \mathrm{mg} / \mathrm{ml})$ was then added to the culture well. 
The morphological changes following NGF treatment were observed after $0,24,36$ and $72 \mathrm{~h}$ using an inverted microscope (Olympus, Tokyo, Japan). Neurites that were $>2$-fold the length of the cell bodies were used to classify the cells as neuron-like, as were multiple neuritis. The rate of differentiation into neuron-like cells was calculated by observation. Images were obtained from five wells to give the mean value.

Immunocytochemistry. Following treatment, cells adhering to the glass coverslips were removed from the 24-well plates and washed in $0.01 \mathrm{M}$ phosphate-buffered saline (PBS). The cells were then fixed in $4 \%$ paraformaldehyde, and exposed (10 $\mathrm{min}$ ) to $0.1 \%$ Triton $\mathrm{X}-100 / \mathrm{PBS}$ (PBST) to permeabilize the cells. Goat serum (10\% in PBS) was subsequently added for $30 \mathrm{~min}$ following the removal of the PBST to block non-specific binding sites in the cells. One drop of rabbit anti-rat microtubule-associated protein 2 antibody $(1 \mathrm{mg} / \mathrm{ml}$, Beijing Bo'ao Biological Co., Ltd., Beijing, China) was then added to the coverslips, which were incubated overnight in a humidified container at $4^{\circ} \mathrm{C}$. The following morning, the coverslips were washed and a drop of FITC-labeled goat antirabbit IgG (2 mg/ml; Beijing Bo'ao Biotechnology Co., Ltd., Beijing, China) was added to the cells and incubated at $37^{\circ} \mathrm{C}$ for $20 \mathrm{~min}$. The coverslips were sealed with anti-quenching mounting medium (Beijing Bo'ao Biotechnology Co., Ltd.). A negative control was created by using PBS instead of the primary antibody. The cells were observed under a fluorescence microscope (Olympus).

Establishment of the oxygen/glucose deprivation (OGD) model. The model was established using an improved method, as described by Guo et al (24). Briefly, cell culture flasks were placed in sealable glassware. Sterile water $(100 \mathrm{ml})$ was injected into the glassware and sodium sulfoxylate (40 g) was also placed in the glassware for oxygen removal. The glassware was then sealed with a rubber tube to keep the atmosphere in the bottle at $\mathrm{CO}_{2} 5 \%, \mathrm{~N}_{2} 95 \%$. Glucose-free fetal bovine serum (10\%) DMEM was added to the cell culture bottles, as well as sodium sulfoxylate (final concentration $1 \mathrm{mM}$ ), in order to continue culturing of PC12 cells. The hypoxia chamber was then placed in an incubator and maintained at $37^{\circ} \mathrm{C}$.

Exogenous ActA and detection of the cell survival rate using the MTT assay. Cells were cultured for 3, 6, 9, 12 and $16 \mathrm{~h}$ in hypoxic conditions, and suspended $(100 \mu \mathrm{l})$ in wells of culture plates at a density of $5 \times 10^{4}$ cells $/ \mathrm{ml}$. Cells were then incubated in $5 \% \mathrm{CO}_{2}$ at $37^{\circ} \mathrm{C}$, and recombinant human ActA (rhActA) was added at concentrations of $10,20,30,50$ or $100 \mu \mathrm{mol} / \mathrm{ml}$. When the cells reached confluence, the MTT solution $(5 \mathrm{mg} / \mathrm{ml}$; $20 \mu \mathrm{l}$ ) was added to each well and cultured for a further $4 \mathrm{~h}$. The MTT solution was then removed and dimethyl sulfoxide $(150 \mu \mathrm{l})$ was added to each well. After the plates were agitated on a table concentrator for $10 \mathrm{~min}$, the optical density at $490 \mathrm{~nm}$ was measured to determine the cell survival rate (\%), calculated as: (light absorbance at $490 \mathrm{~nm} \times 100 \%$ in the experimental group)/(light absorbance at $490 \mathrm{~nm} \times 100 \%$ in the control group). Experiments were repeated three times.

Hoechst 33342 staining assay. Following cell culture for 3, 6, 9, 12, 16 and $24 \mathrm{~h}$, scratched coverslips were placed into 12-well plates. Cells $\left(5 \times 10^{4} / \mathrm{ml}\right)$ were then added to each well and were subjected to OGD, as described above. The cells were fixedy by removing the culture medium and replacing it with $0.5 \mathrm{ml}$ $95 \%$ ethanol. After being washed twice with PBS, $0.5 \mathrm{ml}$ of Hoechst 33342 staining solution was added to the cells. The coverslips were mounted in a fluorescence anti-quenching mounting medium, and the cells were observed under a fluorescence microscope. Hoechst 33342 staining revealed that the nuclei of apoptotic cells appeared bright blue and condensed. The cells were quantified as percentage cells undergoing apoptosis, calculated as: apoptotic cell number/total cell number under the x100 field of vision x 100. Counts were repeated three times to establish a mean value.

Western blotanalysis of ActAIIR, Smad3, Smad4 and caspase-3 in PC12 cells. Culture medium was replaced with $1 \mathrm{X}$ sodium dodecyl sulfate (SDS) sample buffer after PC12 cells under OGD were exposed to rhActA. The cells were scraped from the plates and transferred to centrifuge tubes, where they were sonicated and boiled for $5 \mathrm{~min}$. Samples were centrifuged at $12,000 \mathrm{rpm}$ for $5 \mathrm{~min}$ and the supernatant was removed. The pellets were resuspended, separated using electrophoresis, and transferred to a membrane. The membrane was then placed in a blocking solution (5\% skim milk powder) and probed with rabbit anti-rat primary antibodies (1:200) against ActAIIR, Smad3, Smad4, pro-caspase-3, active caspase-3 and mouse anti-rat $\beta$-actin monoclonal antibody $(200 \mu \mathrm{g} / \mathrm{ml}$, Santa Cruz Biotechnology, Inc., Santa Cruz, CA, USA). The membrane was incubated overnight at $4^{\circ} \mathrm{C}$ and washed three times the following morning (5 min each). Following this washing step, the membranes were incubated with horseradish peroxidase (HRP)-conjugated goat anti-rabbit secondary antibody (1:1,000, Santa Cruz Biotechnology) and incubated subsequent to agitation for $2 \mathrm{~h}$ at $37^{\circ} \mathrm{C}$. The membranes were then washed three times in $0.1 \%$ Tween-20/Tris-buffered saline (TTBS) cleaning solution, ( $5 \mathrm{~min}$ ), and then in TBS alone for $5 \mathrm{~min}$. Band absorbance was measured with a gelatin image analysis system (Olympus) and the absorbance ratio was calculated against the absorbance for the $\beta$-actin band. Experiments were repeated three times.

Statistical analysis. Results are shown as the mean \pm SD. Statistical analysis was conducted using SPSS 13.0 software (SPSS; Chicago, IL, USA). The difference between groups was analyzed using a one-way analysis of variance, and multiple comparisons were conducted using the SNK-q method. $\mathrm{P}<0.05$ indicated a statistically significant difference.

\section{Results}

\section{Morphological analysis of differentiated PC12 cells}

PC12 cell morphology. Microscopy revealed that after $12 \mathrm{~h}$ in culture, PC12 cells had still not adhered to the culture flask. After $36 \mathrm{~h}$, the cells had adhered and began to rapidly divide, until confluence was reached after $72 \mathrm{~h}$ (Fig. 1).

Nerve growth factor-induced differentiation of PC12 cells into neuron-like cells. NGF induced PC12 cells to differentiate into neuron-like cells after $24 \mathrm{~h}$. Synapses formed between PC12 cells, and after $36 \mathrm{~h}$ axons appeared to grow longer and thicker. After $72 \mathrm{~h}$, the length of the axons was $>5$-fold the 


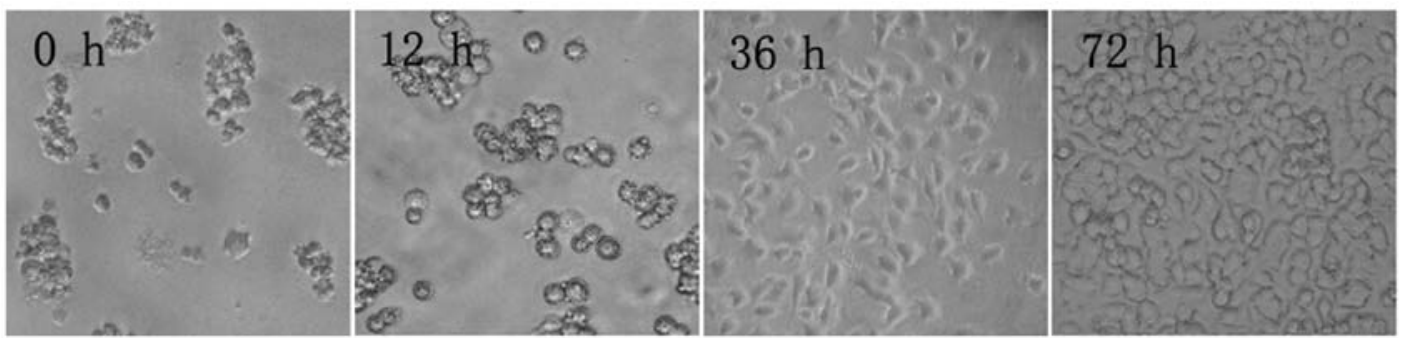

Figure 1. PC12 cell morphology at different time points during culture (inverted microscope, $\mathrm{x} 100$ ). After $12 \mathrm{~h}, \mathrm{PC} 12$ cells did not adhere to the flask walls, but congregated, assuming a semi-suspension state. After $36 \mathrm{~h}, \mathrm{PC1} 2$ cells assumed an elliptical or polygonal shape, tending to congregate in clusters. After $72 \mathrm{~h}$, PC12 cells entered an exponential growth phase, in which cells grew rapidly, no longer congregated, and had a strong optical refraction.
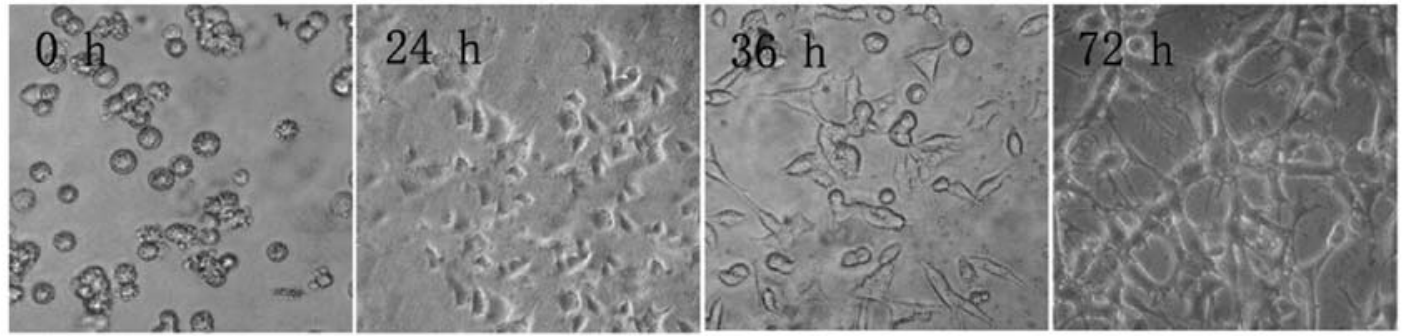

Figure 2. Nerve growth factor (NGF) successfully induced the differentiation of PC12 cells into neuron-like cells (inverted microscope, x100). After $24 \mathrm{~h}$ of NGF induction, $\mathrm{PC} 12$ cells began to grow short neurites. Following $36 \mathrm{~h}$ of induction, the neurites became thicker and increased in number. The length of each axon was $>5$-fold the length of cell bodies at $72 \mathrm{~h}$. These axons became interlaced with each other as well as with dendrites into a network. At this point, the PC12 cells demonstrated typical neuronal morphology.

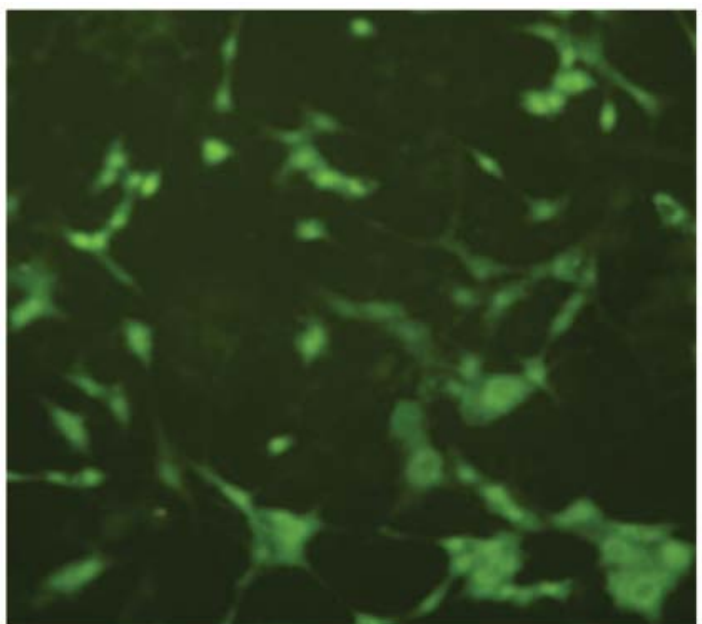

Figure 3. PC12 cell expression of microtubule-associated protein 2 (MAP2). After $72 \mathrm{~h}$ of nerve growth factor induction (immunofluorescence staining, x400), MAP2 had a scattered distribution, showing multiforms with comparatively long synapses.

length of the cell bodies. These axons were interlaced into a network and demonstrated neuronal characteristics. These neuronal-like cells accounted for $>95 \%$ of the culture (Fig. 2).

After $72 \mathrm{~h}$ post-NGF induction of PC12 cells, immunofluorescence staining showed that cells expressed microtubule-associated protein 2 (MAP2) (Fig. 3).

Rate of cell survival after PC12 cells were subjected to $O G D$. An MTT assay revealed that after $3 \mathrm{~h}$ of OGD, the survival rate of $\mathrm{PC} 12$ cells was reduced and continued to decrease with the length of OGD $(\mathrm{P}<0.05$; Fig. 4).

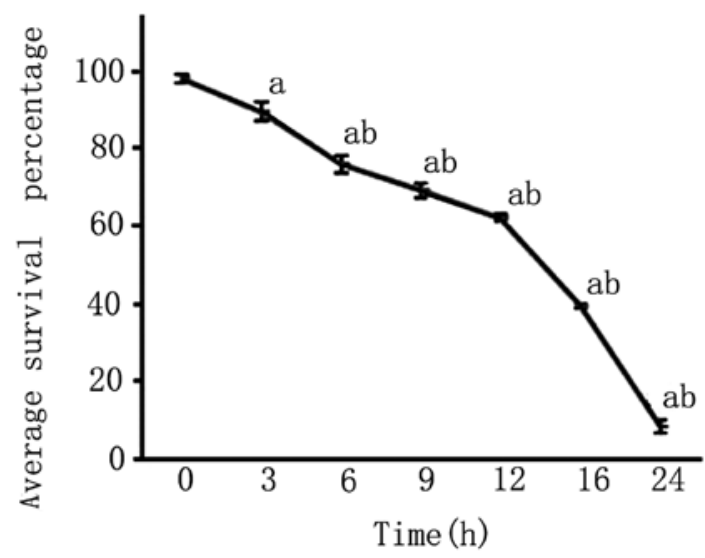

Figure 4. PC12 cell survival rate at different time points after oxygen/glucose deprivation (OGD). The survival rate was detected with the MTT assay. Data are expressed as mean $\pm \mathrm{SD}$, and multiple comparisons were expressed using the SNK-q method. ${ }^{\text {a }} \mathrm{P}<0.05$, vs. $0 \mathrm{~h}$; ${ }^{\text {b }} \mathrm{P}<0.05$ vs. $3 \mathrm{~h}$.

After PC12 cells were subjected to 3 and $6 \mathrm{~h}$ of OGD, apoptotic cells were observed, as detected by condensed nuclei visualized by Hoechst 33342 staining. After 9 h, apoptotic cells increased in number. After $12 \mathrm{~h}$ of OGD, the majority of cells appeared bright, pyknotic, heavily stained and exhibited apoptotic blebs. The majority of the cells died after $24 \mathrm{~h}$ of OGD and very few normal cells were evident (Figs. 5 and 6).

The effect of exogenous ActA on injured PC12 cells after OGD rhActA increased the survival rate of $\mathrm{PC} 12$ cells after $O G D$. As shown above, the cell survival rate of PC12 cells 

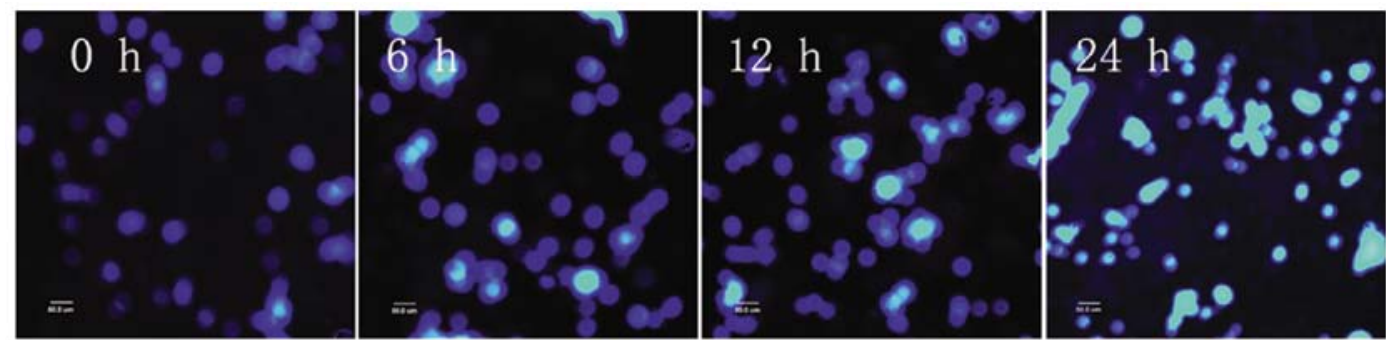

Figure 5. Effect of oxygen/glucose deprivation (OGD) on PC12 cells at different time points (Hoechst 33342 fluorescence staining, x100). The nuclei of the apoptotic cells became bright blue and condensed at different time points. Apoptotic cells were not found in the control group (0 h). After $6 \mathrm{~h}$ of OGD, a small number of apoptotic cells were evident. The apoptotic cell number increased significantly after $12 \mathrm{~h}$ of OGD. The majority of cells had died after $24 \mathrm{~h}$ of OGD.

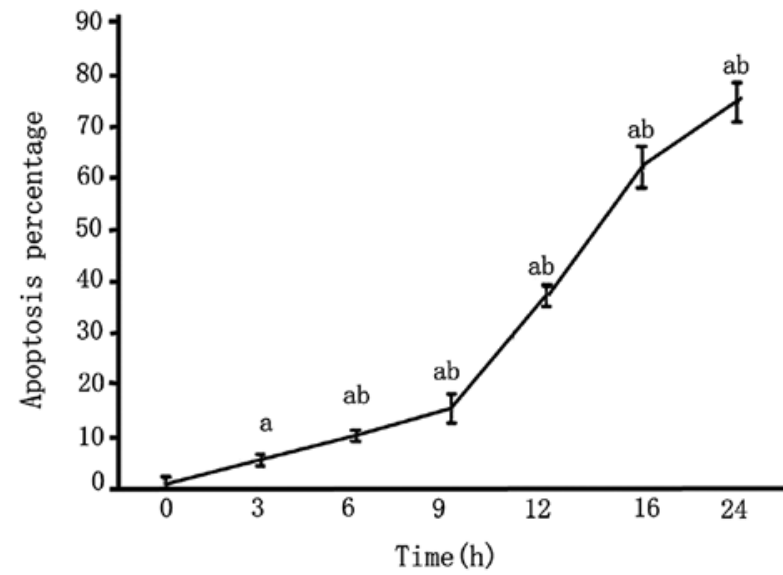

Figure 6. Effect of oxygen/glucose deprivation (OGD) on apoptosis in PC12 cells at different time points. The apoptotic rate was detected with Hoechst 33342 fluorescence staining, and the cells were quantified. Data are expressed as mean $\pm \mathrm{SD}$ and multiple comparisons were made using the SNK-q method. Experiments were repeated three times. ${ }^{a} \mathrm{P}<0.05$ vs. $0 \mathrm{~h}$; ${ }^{\mathrm{b}} \mathrm{P}<0.05$ vs. $3 \mathrm{~h}$.

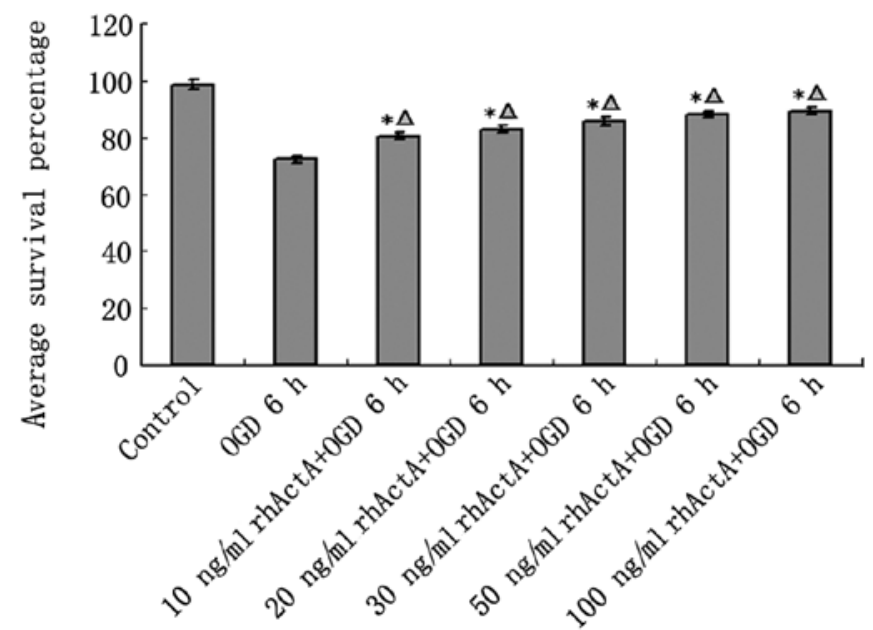

Figure 7. MTT assay for the viability of PC12 cells subjected to oxygen/ glucose deprivation (OGD) in the presence of different concentrations of exogenous rhActA $(0,10,20,30,50$ and $100 \mathrm{ng} / \mathrm{ml})$. OGD $6 \mathrm{~h}$ represents the group treated with $0 \mathrm{ng} / \mathrm{ml}$ exogenous rhActA. * $\mathrm{P}<0.05$ vs. control group, ${ }^{\triangle} \mathrm{P}<0.05$ vs. OGD $6 \mathrm{~h}$ group.
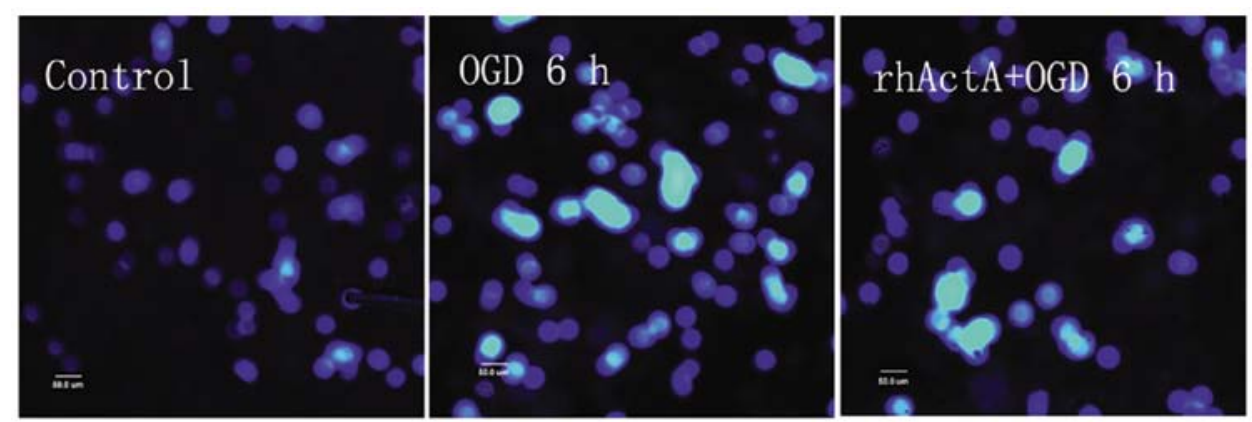

Figure 8. Hoechst 33342 staining for apoptosis in PC12 cells under oxygen/glucose deprivation (OGD) stimulated by rhActA (100 ng/ml) compared with the control group under OGD alone. The nuclei in the control group were elliptical and the chromatin was evenly stained. The apoptotic cell number in the OGD $6 \mathrm{~h}$ group markedly increased and endonuclear chromatin was evenly distributed, showing characteristically bright and condensed nuclei. Nuclear shapes in the rhActA + OGD $6 \mathrm{~h}$ group were found to be less regular, with some bright and condensed nuclei as well (x400).

under OGD was markedly lower than that of the control group. However, this cell death was decreased after $24 \mathrm{~h}$ of $\operatorname{rhActA}$ stimulation. The cell survival rate after $6 \mathrm{~h}$ was increased in the rhActA + OGD group compared with the OGD group. Furthermore, the survival rate was positively correlated with the final concentration of rhActA. The cell survival rate in the rhActA (100 ng/ml) group was slightly higher than that of the
$50 \mathrm{ng} / \mathrm{ml}$ group, however, this difference was not significant. A comparison of the cell survival rate in each group is shown in Fig. 7.

rhActA prevented apoptosis after OGD in PC12 cells. Although most of the nuclei in the control group were not condensed or showed signs of apoptosis, a small number of apoptotic cells were observed (Fig. 8). Apoptosis was evident 


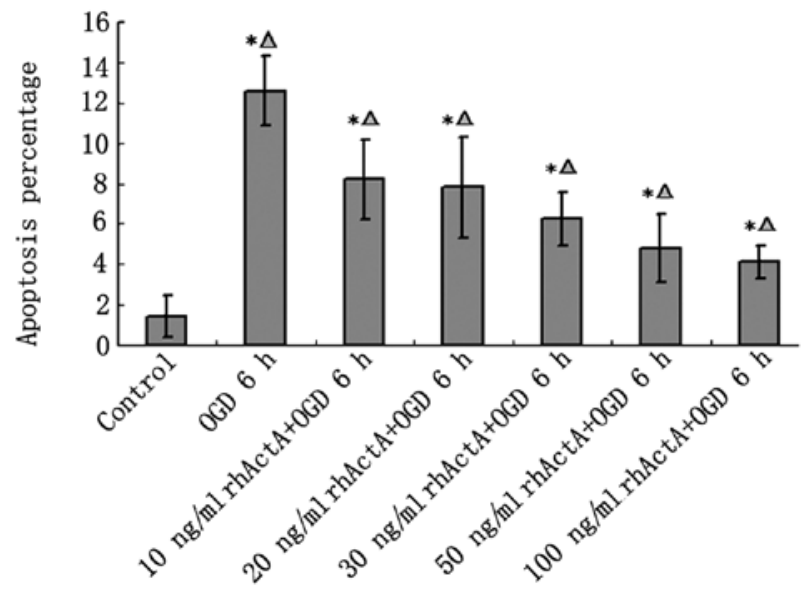

Figure 9. Hoechst 33342 staining for the apoptosis in PC12 cells subjected to different concentrations of exogenous rhActA $(0,10,20,30,50$ and $100 \mathrm{ng} / \mathrm{ml}$ ) after oxygen/glucose deprivation (OGD). ${ }^{*} \mathrm{P}<0.05$ vs. control group, ${ }^{\triangle \mathrm{P}}<0.05$ vs. OGD $6 \mathrm{~h}$ group.

\begin{tabular}{|c|c|c|c|}
\hline Control & OGD & rhActA+OGD & \\
\hline & $B=$ & $c$ & Pro-caspase 3 \\
\hline & & & Cleaved caspase 3 \\
\hline & & $\bar{L}$ & $\beta$-actin \\
\hline
\end{tabular}

Figure 10. The expression of caspase-3 after stimulation with rhActA. After stimulating PC12 cells with $100 \mathrm{ng} / \mathrm{ml} \mathrm{rhAct}$, they were subjected to oxygen/glucose deprivation (OGD). After an additional $6 \mathrm{~h}$, the expression of pro-caspase- 3 and active caspase- 3 was detected using western blotting. The expression of these proteins in the rhActA + OGD $6 \mathrm{~h}$ group was lower than that in the OGD alone group.

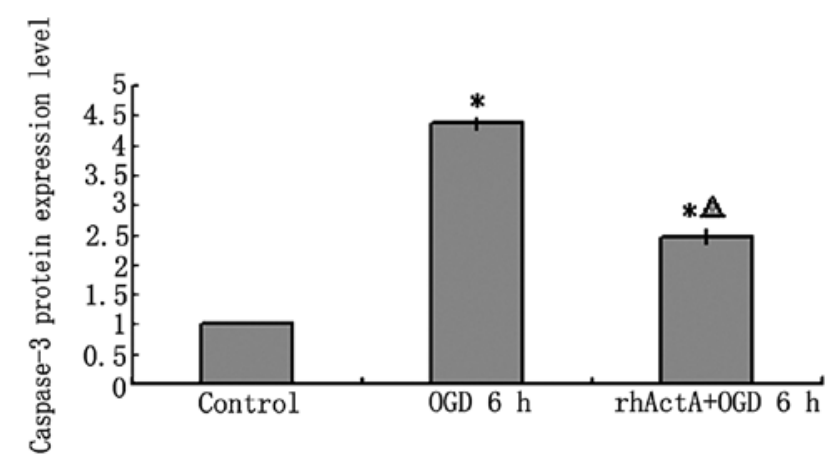

Figure 11. Cleaved-caspase-3 protein expression. After pretreatment of $\mathrm{PC} 12$ cells with rhActA, the cells were subjected to oxygen/glucose deprivation (OGD). Cleaved-caspase-3 protein in the pretreated group was lower than that of the OGD group alone. Data are presented as the mean $\pm \mathrm{SD}(\mathrm{n}=9$, ${ }^{*} \mathrm{P}<0.05$ vs. control; ${ }^{\wedge} \mathrm{P}<0.05$ vs. OGD 6 h group).

in the OGD $6 \mathrm{~h}$ group in which the endonuclear chromatin was unevenly distributed showing typical bright, condensed and densely stained forms. Fewer apoptotic cells were visible in the rhActA + OGD $6 \mathrm{~h}$ group compared with those in the OGD $6 \mathrm{~h}$ group. The apoptotic rate in the OGD $6 \mathrm{~h}$ group was significantly higher than that in the control group (Fig. 9). After $24 \mathrm{~h}$ of rhActA stimulation, PC12 cells exhibited less

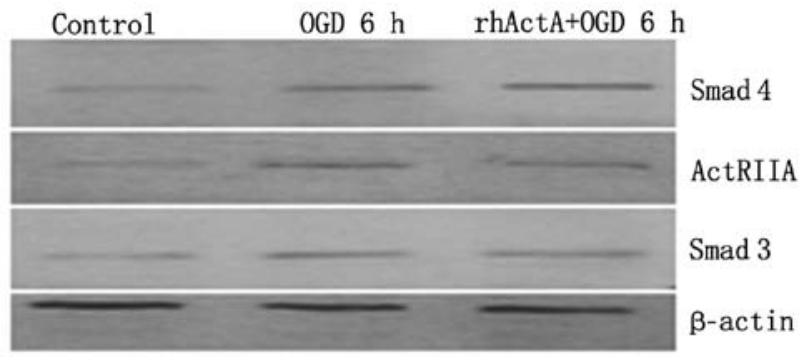

Figure 12. Effects of rhActA pretreatment on the expression of ActRIIA, Smad3 and Smad4 after oxygen/glucose deprivation (OGD). After pretreatment with $100 \mathrm{ng} / \mathrm{ml} \mathrm{rhActA}, \mathrm{PC} 12$ cells were subjected to OGD. The expression of ActRIIA, Smad3 and Smad4 proteins was detected using western blotting. The expression of these proteins in $\operatorname{rhActA}+$ OGD $6 \mathrm{~h}$ group was higher than that in the OGD group.

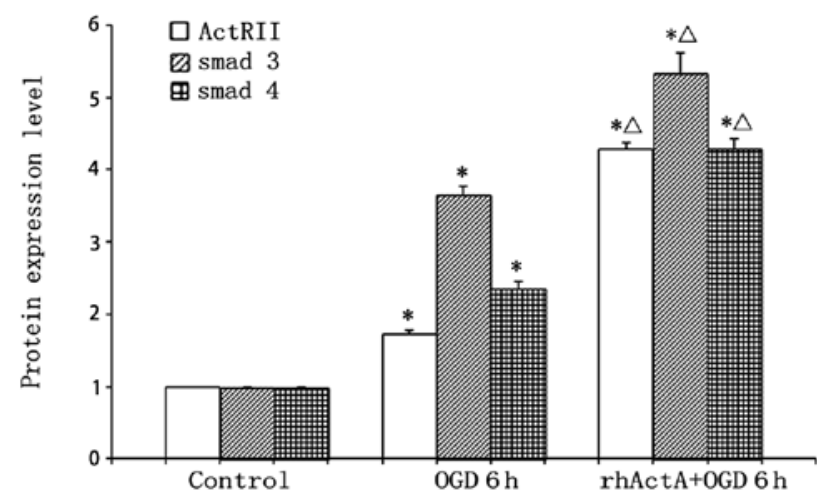

Figure 13. Effects of rhActA pretreatment on the expression of ActRIIA, Smad3 and Smad4 protein expression after oxygen/glucose deprivation (OGD). Pretreatment of PC12 cells with rhActA prior to OGD increased the protein expression of ActRIIA, Smad3 and Smad4 compared with the other groups. Data are presented as the mean $\pm \mathrm{SD}\left(\mathrm{n}=9,{ }^{*} \mathrm{P}<0.05\right.$ vs. control. ${ }^{\triangle} \mathrm{P}<0.05$ vs. OGD $6 \mathrm{~h}$ group).

cell damage compared with that observed in the untreated cells. Furthermore, consistent with the MTT results above, the apoptotic rate appeared to depend on the rhActA concentration. The apoptotic rate in the $\operatorname{rhAct} A(100 \mathrm{ng} / \mathrm{ml})$ group was slightly lower than that observed in the $50 \mathrm{ng} / \mathrm{ml}$ group, although this difference was not significant.

Effect of exogenous ActA on regulating caspase-3 protein expression in PC12 cells following OGD. On the basis of the above results, the rhActA $(100 \mathrm{ng} / \mathrm{ml})+$ OGD $6 \mathrm{~h}$ group was used for subsequent experiments. Results showed that the expression of pro-caspase- 3 and active caspase- 3 after $6 \mathrm{~h}$ of OGD alone was higher than that of the control group not experiencing deprivation $(\mathrm{P}<0.05)$ (Figs. 10 and 11). Furthermore, caspase- 3 expression after $6 \mathrm{~h}$ of OGD alone showed a marked increase compared with that in cells co-stimulated with $\operatorname{rhAct} \mathrm{A}(\mathrm{P}<0.05)$.

Effect of exogenous ActA on ActRIIA, Smad3 and Smad4 protein expression after PC12 cells were subjected to OGD. Protein expression of ActRIIA, Smad3 and Smad4 in the OGD $6 \mathrm{~h}$ group was higher than that in the control group $(\mathrm{P}<0.05)$ (Figs. 12 and 13). By contrast, pretreatment with rhActA significantly decreased the expression of ActRIIA after $6 \mathrm{~h}$ of OGD $(\mathrm{P}<0.05)$ compared with the OGD $6 \mathrm{~h}$ group. 


\section{Discussion}

Results of the present study have shown that ActA is a fundamental regulator of histiocytes, participating in histiocyte growth, as well as aiding in the maintenance of their normal function. The biological activity of ActA is restricted to target cell types, suggesting its tissue specificity. As a neuronal growth factor, ActA has a protective role against many factors, inducing nerve injuries. It has been found that ActA plays an active role in neuronal repair after brain injury (2). Shoji and colleagues (11) have found that activins can increase the synapse number and dendritic crest neck length of seahorse neurons cultured in vitro. Other brain injuries, such as those caused by acute anoxia/ischemia, also cause ActA to increase in expression. Therefore, ActA has been described as an early transient ischemic and anoxic regulatory gene (12). It is confirmed that calcitonin gene-related peptide (CGRP) has a nerve-protective function and is capable of regulating axonal regeneration (13). Act A has been shown to stimulate the expression of DRG in vitro (14), and DRG and CGRP in vivo (15). An increasing number of studies suggest that recombinant activins likely alleviate post-ischemic nerve injury. This mechanism may occur because an activin induces basic fibroblast growth factor (bFGF) expression, and dopaminergic neuron generation. Thus, there may be a synergistic protective effect between recombinant activin and $\operatorname{bFGF}(2,16)$. Of note, previous studies (17) have also revealed that activins regulate apoptosis. For example, ActA has been found to prevent apoptosis in hepatocytes. As a regulatory factor of hepatocyte proliferation, it is able to induce DNA synthesis by affecting mitogens and regulate hepatocyte growth. This effect has been shown to be mediated by activin type I and type II receptors on the cell surface $(17,18)$. The dose-dependent inhibition of ActA on apoptosis confirms the role of ActA in promoting cell survival.

Caspases are cysteine-aspartic proteases that share amino acid similarity and secondary structure cysteine proteases. These proteins are closely associated with ukaryotic apoptosis. Caspase-3 activation is a pivotal point of a number of apoptotic pathways. Furthermore, caspase-3 may be an important effector in ischemic neuronal apoptosis (19) and directly leads to cell death (20). Administration of a caspase-3 inhibitor after $9 \mathrm{~h}$ of mouse cerebral ischemia has been shown to effectively reduce cerebral infarction size (21). Furthermore, after $2 \mathrm{~h}$ of unilateral middle cerebral artery occlusion in mice, the occurrence of cerebral post-ischemic neuronal apoptosis has been shown to be closely associated with caspase-3 activity, as well as increasing split products. Following ischemic reperfusion, caspase-3 protein expression has also been shown to increase to different extents $(22,23)$.

In the present study, we established a novel neuronal-like OGD model that can be used to study the effects of anoxia and ischemia in vitro. This was accomplished by inducing the differentiation of PC12 cells with NGF prior to oxygen and glucose deprivation. Using this novel OGD model, we have demonstrated that there was an increased amount of apoptosis over time, indicating that the OGD model was successful.

We also demonstrated that ActA pretreatment prevented apoptosis and promoted cell viability after OGD. Caspase-3 protein expression in cells was increased after OGD, which was partially abrogated by ActA pretreatment. Additionally, we found that ActA pretreatment increased the expression of ActRIIA, Smad3 and Smad4, even after OGD. This finding suggests that activation of the ActA/Smad signal transduction pathway might prevent neuronal injury due to ischemia and anoxia. The ActA/Smads pathway activation induced by transient ischemic injury in the course of cerebral ischemia may therefore also play a protective role. It is likely through the ActA/Smad signal transduction that ActA protects against cell apoptosis and protects neurons.

In conclusion, our study results suggest that ActA potentially plays a protective role in ischemic and anoxic neuronal injury through the ActA/Smad signal transduction pathway. This protective effect may be mediated in part by downregulating caspase-3 expression. However, how the activation of the ActA/Smad signal transduction pathway inhibits apoptotic processes and caspase- 3 expression remains to be determined. Additional studies are required to elucidate the underlying mechanism of action of the protective effects of ActA.

\section{Acknowledgements}

This study was financially supported by the National Natural Science Foundation of China (no. 30971037), Postdoctoral Foundation of China (no. 2012MS10489), the Natural Science Foundation of Jilin Provincial Science and Technology Department (no. 201015240) and the Department of Education of Jilin Province Project (no. 2013361).

\section{References}

1. Massagué J: TGFbeta in cancer. Cell 134: 215-230, 2008.

2. Tretter YP, Hertel M, Munz B, ten Bruggencate G, Werner S and Alzheimer C: Induction of activin A is essential for the neuroprotective action of basic fibroblast growth factor in vivo. Nat Med 6: 812-815, 2000.

3. Lin X, Duan X, Liang YY, et al: PPM1A functions as a Smad phosphatase to terminate TGFbeta signaling. Cell 125: 915-928, 2006.

4. Ling N, Ueno N, Ying SY, et al: Inhibins and activins. Vitam Horm 44: 1-46, 1988.

5. Munz B, Tretter YP, Hertel M, Engelhardt F, Alzheimer C and Werner S: The roles of activins in repair processes of the skin and the brain. Mol Cell Endocrinol 180: 169-177, 2001.

6. Ageta H, Murayama A, Migishima R, et al: Activin in the brain modulates anxiety-related behavior and adult neurogenesis. PLoS One 3: e1869, 2008.

7. Tsuchida K, Nakatani M, Uezumi A, Murakami T and Cui X: Signal transduction pathway through activin receptors as a therapeutic target of musculoskeletal diseases and cancer. Endocr J 55: 11-21, 2008.

8. Schneyer AL, Sidis Y, Gulati A, Sun JL, Keutmann H and Krasney PA: Differential antagonism of activin, myostatin and growth and differentiation factor 11 by wild-type and mutant follistatin. Endocrinology 149: 4589-4595, 2008.

9. Zhou WJ and Hu ZP: Expression of Smad 2 and Smad 4 proteins in brain tissue following cerebral ischemia/reperfusion in gerbils. Guoji Shenjing Bing Xue Shenjing Waike Zazhi 35: 112-114, 2008 (In Chinese).

10. Tsuchida K, Nakatani M, Hitachi K, et al: Activin signaling as an emerging target for therapeutic interventions. Cell Commun Signal 7: 15, 2009

11. Shoji-Kasai Y, Ageta H, Hasegawa Y, Tsuchida K, Sugino H and Inokuchi K: Activin increases the number of synaptic contacts and the length of dendritic spine necks by modulating spinal actin dynamics. J Cell Sci 120: 3830-3837, 2007.

12. Mukerji SS, Katsman EA, Wilber C, Haner NA, Selman WR and Hall AK: Activin is a neuronal survival factor that is rapidly increased after transient cerebral ischemia and hypoxia in mice. J Cereb Blood Flow Metab 27: 1161-1172, 2007. 
13. Li XQ, Verge VM, Johnston JM and Zochodne DW: CGRP peptide and regenerating sensory axons. J Neuropathol Exp Neurol 63: 1092-1103, 2004.

14. Cruise BA, Xu P and Hall AK: Wounds increase activin in skin and a vasoactive neuropeptide in sensory ganglia. Dev Biol 271: $1-10,2004$.

15. Xu P, Van Slambrouck C, Berti-Mattera L and Hall AK: Activin induces tactile allodynia and increases calcitonin gene-related peptide after peripheral inflammation. J Neurosci 25: 9227-9235, 2005.

16. Müller MR, Zheng F, Werner S and Alzheimer C: Transgenic mice expressing dominant-negative activin receptor IB in forebrain neurons reveal novel functions of activin at glutamatergic synapses. J Biol Chem 281: 29076-29084, 2006.

17. Yasuda $\mathrm{H}$, Mine $\mathrm{T}$, Shibata $\mathrm{H}$, et al: Activin A: an autocrine inhibitor of initiation of DNA synthesis in rat hepatocytes. J Clin Invest 92: 1491-1496, 1993.

18. Chen W, Woodruff TK and Mayo KE: Activin A induced Hep G2 liver cell apoptosis: involvement of activin receptors and smad proteins. Endocrinology 141: 1263-1272, 2000.
19. Yuan $\mathrm{J}$ and Yankner BA: Apoptosis in the nervous system. Nature 407: 802-809, 2000.

20. Gurney ME, Tomasselli AG and Heinrikson RL: Neurobiology. Stay the executioner's hand. Science 288: 283-284, 2000.

21. Lee JM, Grabb MC, Zipfel GJ and Choi DW: Brain tissue responses to ischemia. J Clin Invest 106: 723-731, 2000.

22. Benchoua A, Guégan C, Couriaud C, et al: Specific caspase pathways are activated in the two stages of cerebral infarction. J Neurosci 21: 7127-7134, 2001.

23. Harrison DC, Davis RP, Bond BC, et al: Caspase mRNA expression in a rat model of focal cerebral ischemia. Brain Res Mol Brain Res 89: 133-146, 2001.

24. Guo HL, Xu ZX and Li XH: Use of RNAi silencing to target preconditioned glial cell line-derived neurotrophic factor in neuronal apoptosis. Neural Regen Res 6: 510-516, 2011. 